\title{
COMPLEXOS ENERGÉTICOS: UMA ANÁLISE DA NOVA COMPOSIÇÃO DAS MATRIZES DE ENERGIA DO BRASIL E DO MUNDO
}

\author{
Claudia Gomes de Farias ${ }^{1}$ \\ Isabel Lausanne Fontgalland ${ }^{2}$
}

RESUMO: A importância da tecnologia usada pela energia eólica se destaca não apenas como uma fonte renovável, mas também como uma forma de reduzir a emissão de GEE - gases de efeito estufa -. Sabe-se que o setor de energia elétrica se situa entre os mais importantes em termos de emissão de GEE e, por isso, inúmeras ações foram feitas nas últimas duas décadas. Isso posto, os processos convencionais de geração de energia elétrica (hidroelétricas, termoelétricas, etc.) estão entre os principais responsáveis pelas emissões de $\mathrm{CO}_{2}$, qualificando assim as novas estratégias de fomento de energia renováveis. Sob este contexto, esse trabalho apresenta o objetivo de estudar os efeitos econômicos e ambientais que o crescimento da energia eólica ocasionou ao país, comparados aos do setor hidrelétrico e termoelétrico, oportunizando um debate dos recentes estudos sobre energia eólica. Para tanto, foi realizada uma síntese dos aspectos mais importantes relacionados aos critérios econômicos e ambientais e posterior análise crítica. A partir das leituras e comparações realizadas, verificou-se as causas e as consequências deste tipo de energia vis-à-vis dos impactos ambientais relativos às outras formas de energia quais sejam as hidrelétricas e termoelétricas. Por fim, à luz da metodologia adequada, foi possível verificar os aspectos inerentes a cada tipo de fonte energética de modo a relacionar impactos e mitigar os efeitos negativos indesejados já conhecidos.

Palavras-Chave: Energia renovável. Impactos ambientais. Complexo eólico.

ABSTRACT: The importance of the technology used by wind energy stands out not only as a renewable source, but also as a way to reduce the emission of GHG - greenhouse gases. It is known that the electric power sector is among the most important in terms of GHG emissions and, therefore, numerous actions have been taken in the last two decades. That said, the conventional processes of power generation (hydroelectric, thermoelectric, etc.) are among the main responsible for $\mathrm{CO}_{2}$ emissions, thus qualifying the new strategies to promote renewable energy. Under this context, this work presents the objective of studying the economic and environmental effects that the growth of wind energy has caused to the country, compared to the hydroelectric and thermoelectric sectors, providing an opportunity for a debate of the recent studies on wind energy. For this, a synthesis of the most important aspects related to the economic and environmental criteria and subsequent critical analysis was performed. From the readings and comparisons made, the causes and consequences of this type of energy were verified vis-à-vis the environmental impacts related to other forms of energy, namely hydroelectric and thermoelectric. Finally, in light of the appropriate methodology, it was possible to verify the aspects inherent to each type of energy source in order to relate impacts and mitigate the negative undesirable effects already known.

Keywords: Renewable energy. Environmental impacts. Wind complex.

\footnotetext{
${ }^{\mathrm{I}}$ Professora do departamento de Administração da Universidade Federal de Campina Grande - PB. Cv Lattes: http://lattes.cnpq.br/2922885697021371. Doutoranda do Programa de Pós-Graduação em Engenharia e Gestão de Recursos Naturais - PPGERN.

2 Professora Títular da UFCG. Professora e Orientadora do PPGERN. Cv Lattes: http://lattes.cnpq.br/3447455428798868.
} 


\section{INTRODUÇÃO}

A problemática das matrizes energéticas mundiais reflete a questão sine qua non da trajetória de dependência entre os países industriais. Essa discussão derroca na busca de solvência entre o volume de energia produzida in-shore e off-shore. Estes fatos são delimitantes dada a natureza de grande parte das políticas desenvolvimentistas mundiais as quais apontaram um cenário de uso intensivo dos recursos naturais energéticos. Para além disso, o contínuo esgotamento das reservas mundiais de fósseis e as previsões de esgotamento das atuais formas de energia, juntamente com as preocupações relativas ao impacto ambiental, mudaram a promoção do processamento e utilização de energias no mundo. No Brasil, em particular, a expansão da produção doméstica de petróleo e gás natural em 2002, o reposicionou, no centro do mundo industrial, de tal forma que fora considerado o "celeiro exportador do mundo". Essa trajetória impactou em escolhas de termos da matriz enérgica e, como tendência, se reverteu, nas primeiras décadas em mundo, numa perspectiva de aumento parcelar renovável da energia enovolvida.

As mudanças climáticas têm sido alvo de estudos recentes, visto que seus impactos acarretam mudanças significativas no meio ambiente. A busca de fontes menos impactantes e menos gastadoras de recursos naturais também tem influenciado na redução dos recursos hídricos e, por conseguinte, uma distribuição de energia mais limpa e barata. Desse fato resulta-se a importância de estudos acerca de tecnologias renováveis, além da visualização de redução de emissão de gases de efeito estufa (GEE).

No Brasil, a escolha por processos convencionais de geração de energia elétrica (hidroelétricas, termoelétricas, etc.), vem se esgotando ao longo de um crescente desenvolvimento industrial, 1945-1970; 1970-1983; 1992-2002; 2002-2012, cuja demanda de energia elétrica tem disparado substancialmente, concorrentemente às tecnologias de inovação de processos produtivos em paralelo ao consumo residencial crescente. Diante desse contexto, a necessidade de fontes de energia renovável e limpa passou a ter caráter essencial e o desenvolvimento de tecnologias que apresentem características sustentáveis foram se tornando eminente ao longo dos anos. Em virtude dos avanços ocorridos nas mais diversas escalas, a adoção de novas formas de produção de energia 
elétrica se tornou debate em todos os níveis da sociedade, bem como nas conferências mundiais que ocorrem periodicamente entre as nações. Assim, a necessidade de mudar a matriz de utilização e consumo de energia tornou eminente a vinda de novas fontes de energia se destacando as opções de energia limpa e renovável.

\section{Estado contemporâneo da matriz energética brasileira e a inclusão da energia eólica}

De acordo com TolmasQuim et al. (2007) "o uso de energia no Brasil começou a apresentar incrementos elevados a partir do término da II Guerra Mundial, impulsionado pelo expressivo crescimento demográfico, por uma urbanização acelerada, pelo processo de industrialização e pela construção de uma infraestrutura de transporte rodoviário de característica energo-intensiva".

No começo do milênio, e mais precisamente em 2002, o Brasil encara uma nova política de energia onde os incentivos são voltados para biomassas e biocombustíveis provenientes de oleaginosas. Esse processo foi chamado: nova matriz energética. A energia eólica foi apontada como um dos importantes vetores desta nova onda, dado a costa brasileira nordestina produzir ventos importantes e apontados no relatório IRENA como parte do novo mercado de produção de energia on-shore.

A energia eólica é considerada energia limpa pois existe no movimento do vento, ou seja, na cinética contida nas massas de ar na atmosfera. A energia total fornecida pela energia eólica ao redor da Terra pode ser estimada com base na suposição de que cerca de $2 \%$ da energia solar absorvida pela Terra e é convertida em energia cinética do vento. Embora esse percentual pareça pequeno, é cem vezes a capacidade instalada anual das usinas eólicas no mundo (CRESESB, 2014). O uso dessa energia para fins mecânicos, como dirigir veleiros, moinhos rotativos, bombear água ou moer grãos, é muito antigo (Mauad, Ferreira, \& Trindade, 2017). Por outro lado, foi utilizado muito mais tarde para obter energia elétrica. Houve relatos de pesquisas no século XIX, mas só se consolidou em 1970, quando foi necessário devido à crise do petróleo (REIS, 20II)

A conversão de energia eólica em elétrica inclui o uso de turbinas eólicas para converter a energia translacional em energia cinética rotacional. Daí a importância do principal componente da conversão desta energia: o vento (massa de ar em movimento), cujo movimento decorre do aquecimento diferente da camada de ar pelo 
sol (densidade e gradiente de pressão diferentes) e o movimento da terra. Isso deve-se as propriedades físicas do ar, que, quando está aquecido, se expande mais do que quando está frio, tornando-se menos denso e tendendo a subir, sendo substituído pelo seu componente mais denso, o ar frio. Assim, o sol transfere mais energia para áreas onde os raios solares são perpendiculares ou próximos ao ângulo reto e por este motivo, a temperatura nos trópicos do equador (onde o ângulo de ataque do sol é de $90^{\circ}$ ) é mais alta que nos polos. Considerando, então, que a terra perto do equador é mais quente do que perto dos polos, o ar frio de superfície circula dos polos para o equador para substituir o ar quente que sobe nos trópicos e viaja pela alta atmosfera até os polos, fechando assim a circulação.

Além do seu comportamento ser regido pelas suas formas de geração, o vento também é influenciado por outros aspectos naturais, tais como: latitude, altitude, características topográficas e rugosidade do solo (CAMPOS, 2004). Percebe-se, desta forma, que a velocidade do vento é extremamente sensível a diversos fatores, fazendo com que a potência extraída deste meio varie proporcionalmente. Assim, a construção de uma usina eólica, são necessários: estudo do terreno e localização, bem como o levantamento de dados através de medições e de outras pesquisas realizadas localmente, para que seja feito um correto dimensionamento do projeto. O comportamento do vento (direção e intensidade) é um estudo necessário e pode ser feito através de anemômetros instalados a Iom do solo, sensores de direção e do tratamento estatístico adequado dos dados, cujos resultados podem ser representados em mapas cartográficos, com isolinhas (de velocidade média, de calmaria, de velocidade máxima e isolinhas de fluxo de potência média ou potência média bruta $(\mathrm{w} / \mathrm{m} 2))$.

Segundo Tuchtenhagen (2014), a curva de maior relevância e a partir da qual todas as outras podem ser obtidas é a da frequência das velocidades, que fornece o período em que uma determinada velocidade foi observada e de acordo com Sansigolo (2005), modelos probabilísticos são usados para modelar a curva de velocidadefrequência porque reproduzem estatisticamente os dados analisados de forma compacta, sendo bastante usado em estudos de energia eólica, a distribuição Weibull.

O diagrama de Weibull, que representa estatisticamente a distribuição da densidade de probabilidade do vento, é usado com frequência porque além de incluir o 
comportamento do vento extremo, também pode descrever vários padrões de comportamento do vento de forma satisfatória. Desta forma, a probabilidade $f(v)$ de ocorrência da velocidade $\mathrm{v}$ do vento, é calculado através da Equação I (TROEN \& PETERSEN, 1989).

Equação I - Probabilidade de ocorrência da velocidade do vento

$$
f(v)=\frac{K}{c} \frac{v}{c}^{k-1} \exp -\frac{v^{k}}{c} \rightarrow K>0 ; c>1 ; v>0
$$

\section{Sendo:}

c - Fator de escalas em unidades de velocidade do vento

$\mathrm{k}$ - Fator de forma adimensional

v - Variável aleatória de velocidade do vento

O fator de forma $k$ está inversamente relacionado à variância $\sigma^{2}$ das velocidades eólicas em torno da média. Portanto, para a noção do gráfico de Weibull, necessita-se das informações de velocidade média (Equação 2) e desvio padrão (Equação 3) do vento. (SANSIGOLO,2005)

Equação 2 - Velocidade média.

$$
v=\mathrm{J} \infty \quad v f(v) d v
$$

Equação 3 - Desvio padrão do vento.

$$
\sigma^{2}=\int_{0}^{\infty}\left(v-\bar{v}^{2} f(v) d\right.
$$

Há vários métodos para a determinar os parâmetros $c$ e k. Um deles, testado e considerado mais preciso por Araújo (1989), é o Método da Velocidade Média (Equação 4) e Desvio padrão (Equação 5):

Equação 4 - Método da Velocidade média.

$$
k=\left(\frac{\sigma}{v}\right)^{-1,086}
$$

Equação 5 - Desvio Padrão

$$
c=(v) / \Gamma\left(1+\left(\frac{1}{k}\right)\right)
$$


Tendo $\Gamma(x)=$ Função Gamma, que é calculada:

Equação 6 - Função Gamma.

$$
\Gamma(x)=\mathbf{J 1} \ln \frac{\mathbf{1}}{\boldsymbol{t}}^{(x-1)} d t \text { sendo } x=\left(1+\frac{1}{k}\right)
$$

Quando $\mathrm{k}=2$, outra curva mais simples é gerada, chamada de distribuição de Rayleigh, que também é usada em projetos eólicos. A Figura I mostra essa distribuição em algimas velocidades médias do vento.

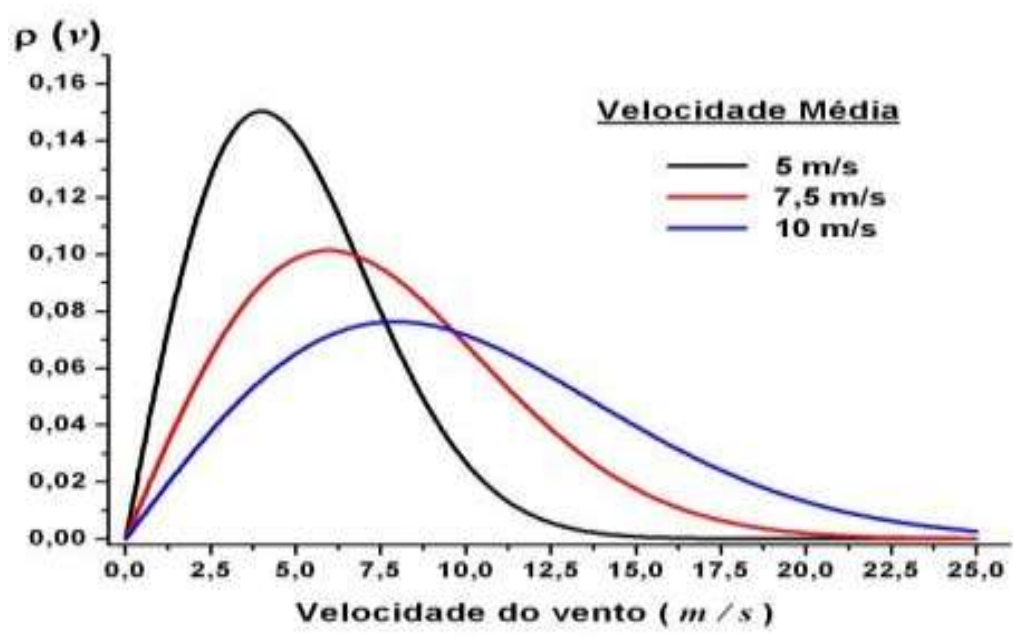

Figura I - Distribuição de Rayleigh

Fonte: adaptado a partir de Ramos (2004)

A velocidade do vento adequada para fins de energia eólica é um dos fatores chaves para a escolha de localização de projetos eólicos, e por esta razão tais estudos são necessários. A energia disponível para uma turbina eólica é a energia cinética associada a uma coluna de ar se movendo a uma velocidade $\mathrm{v}(\mathrm{m} / \mathrm{s})$, passando pela área $\mathrm{A}\left(\mathrm{m}^{2}\right)$ do rotor da turbina, e movendo uma massa $\rho \operatorname{Av}(\mathrm{kg} / \mathrm{s})$, em que $\rho\left(\mathrm{kg} / \mathrm{m}^{3}\right)$ é a massa específica do ar. A energia eólica disponível $\mathrm{P}(\mathrm{W})$ pode então ser calculada pela Equação 7. Esta equação denota que a potência obtida de uma massa de ar é proporcional à três fatores: à área de captação do vento pela turbina, ou seja, ao círculo de área $\mathrm{S}\left(\pi r^{2}\right)$ varrida pela hélice de raio $\mathrm{r}$; à densidade do ar local $(\rho)$; e ao cubo da velocidade $\left(v^{3}\right)$ (CAMPOS,2004). 
Equação 7 - Energia eólica disponível

$$
P=\frac{1}{2} S x \rho \times V^{3}
$$

Onde:

$\rho=$ densidade do ar em $\mathrm{kg} / \mathrm{m} 3$

$\mathrm{V}=$ velocidade do vento $\mathrm{em} \mathrm{m} / \mathrm{s}$

$\mathrm{S}=\pi r^{2}$

\section{Metodologia e modelagem}

Esta pesquisa trata-se de um estudo de revisão bibliográfica com foco informativo. Essa busca de informações e coletas de artigos utilizou critérios explícitos de seleção e de vantagem temporal onde se buscou evidenciar o tema em tela, respeitando o critério de não-exclusividade dos artigos do sistema WEB of Science e ResearchGate. Para tanto, associou-se a economia e as demais áreas do conhecimento em todo o tempo. Também foram aplicadas buscas em plataforma estatísticas e artigos de plataforma ISI e EduCapes publicados.

De acordo com peculiaridades deste sistema, a análise segue os critérios apresentados na Figura 2 a seguir.

Figura 2 - Hierarquia dos critérios utilizados

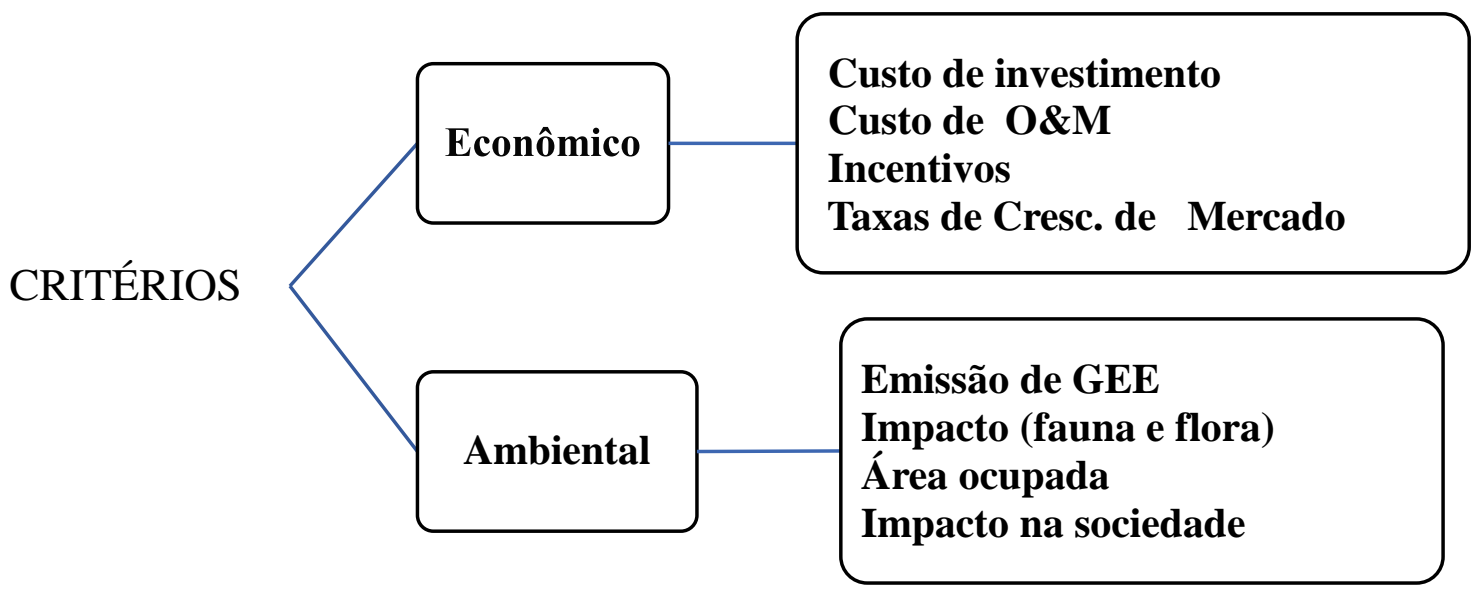

Fonte: autores (2021)

Recentemente, os sistemas energéticos sofreram uma tendência de desenvolvimento caracterizada através das seguintes diretrizes principais de acordo com os 
setores energéticos mais importantes (eletricidade e energia natural, gás, etc), apontando em particular, para a crescente consciencialização da comunidade sobre o impacto ambiental causado por grandes centrais elétricas convencionais, unidas com um maior interesse na distribuição tecnologias de geração baseadas em recursos renováveis e cogeração;

As atividades de planeamento energético como regionais em vez de nacionais. Este documento visa apresentar uma metodologia que relacione o planeamento energético ao longo de um período de intervalo de tempo de algumas décadas.

\section{Análise e Resultados}

O Brasil em termos de capacidade de produção ocupa desde 2014 , a $8^{a}$ posição no ranking de capacidade de produção de energia do globo. Este evoluiu de 5.939 MW para 17.198MW em 2020. Considerando uma matriz enérgica diversificada, temos $79 \%$ desta renovável, contado com uma capacidade eólica de 42.3 Twh. Sendo os dados do IRENA ( International Renewable Energy Agency), tem se destacado com uma matriz limpa de $83 \%$, o que leva a acreditar que a energia fotovotaíca e a energia eólica tem grande difusão.

O panorama destas fontes de recurso pode ser observado pela Figura 3, a seguir.

Figura 3 - Consumo e Utilização de fontes Renovável e Não renovável, respectivamente (2018).

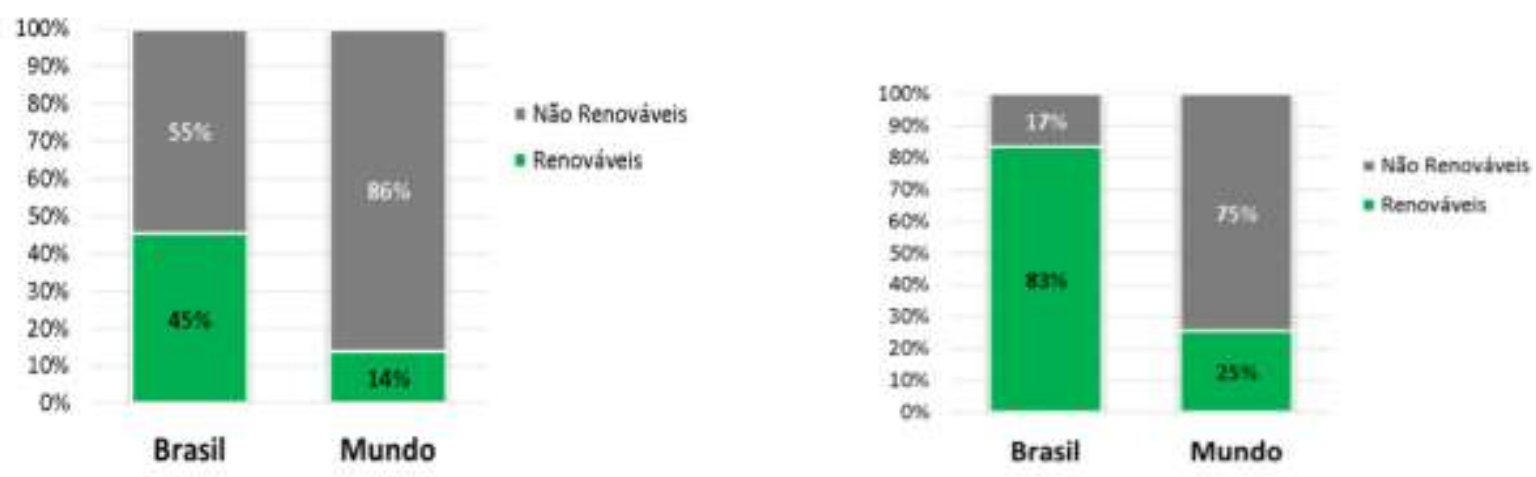

Fonte: IEA (2021)

No resto do mundo, conforme é observado na Figura 3, o consumo de fontes não renováveis de energia ainda está alto e a utilização dessas fontes também se apresenta elevada. O destaque no Brasil é a diversificação da sua matriz. Além disso, a oferta de 
outras categorias de energia renovável em 2020 cresceu $0,7 \%$, enquanto ocorreram quedas na oferta

da maioria das demais fontes energéticas: petróleo e derivados, hidráulica, gás natural e carvão mineral (BEM, 2020), como ilustra a Figura 4.

Figura 4 - Evolução da Matriz Energética nacional - comparativo 2019/2020
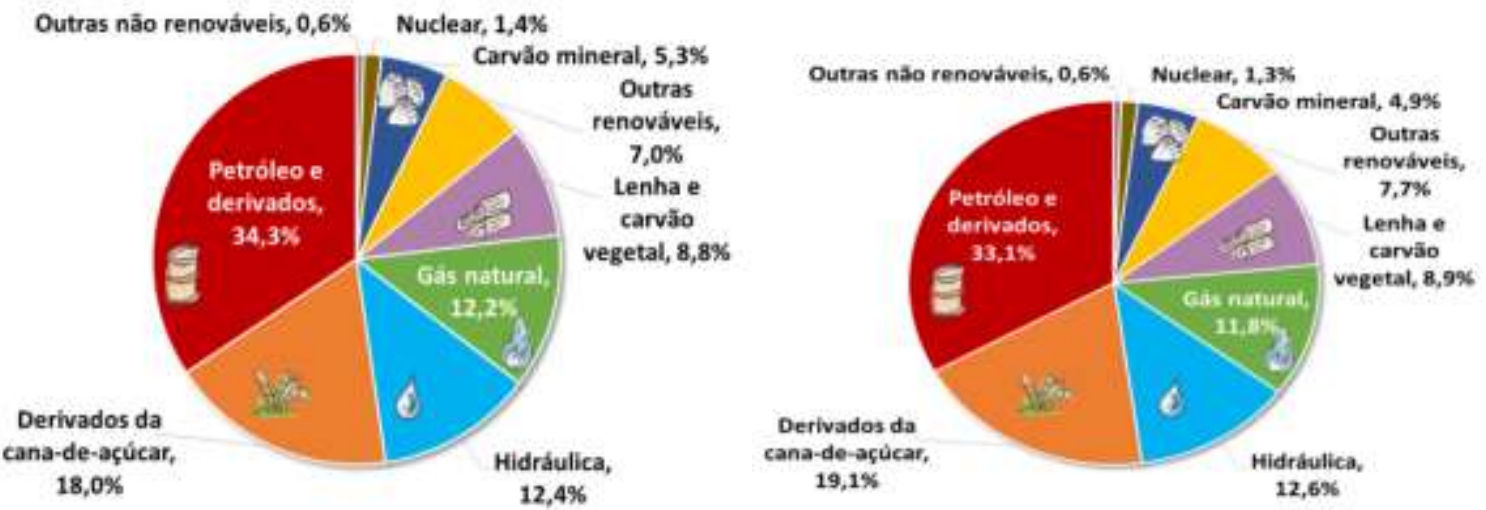

Fonte: (EPE; MME, 2021)

De acordo com a Agência Internacional de Energia, IEA (2021), as adições de capacidade eólica global aumentaram mais de 90\% em 2020. E mesmo com a diminuição do ritmo de crescimento anual do mercado em 2021 e 2022, ainda está 50\% superior à média de 2017-2019. Isso sinaliza que as fontes de energia renovável tendem a se expandir, à medida que a economia global for se recuperando da crise resultante da pandemia da qual o mundo foi e ainda está sendo acometido. O cenário mundial, por conseguinte, aponta para a expansão desta fonte energética tanto em instalações on-shore quanto em offshore e, como pode ser visto na Figura 4 a seguir, as instalações de novos parques estão aumentando.

Figura 4 - Evolução da instalação de novos parques eólicos offshore no mundo entre 2015 e 2018

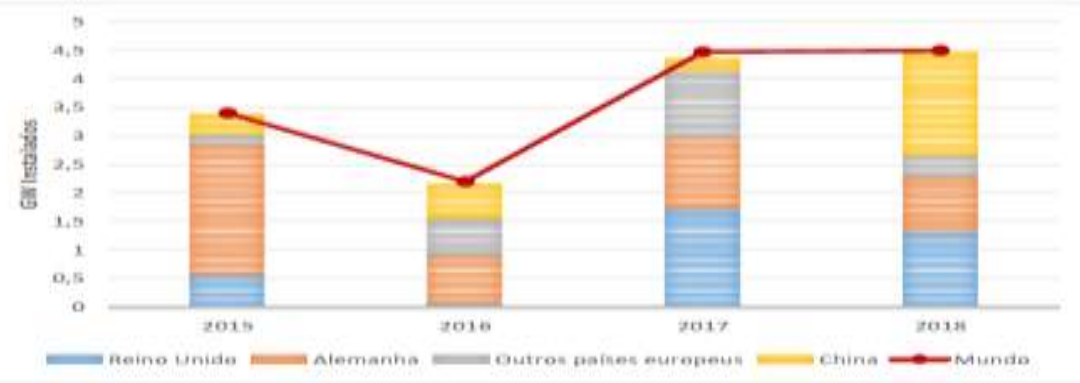

Fonte: ROADMAP Eólica offshore Brasil (2020) 
No que se refere a capacidade de instalação, o quadro mundial destaca o Reino Unido com o maior percentual, por apresentar 34\% dos 23,1 GW já instalados, até 2019, conforme apresentado na Figura 5, a seguir apresentada..

Figura 5 - Capacidade instalada de parques eólicos offshore

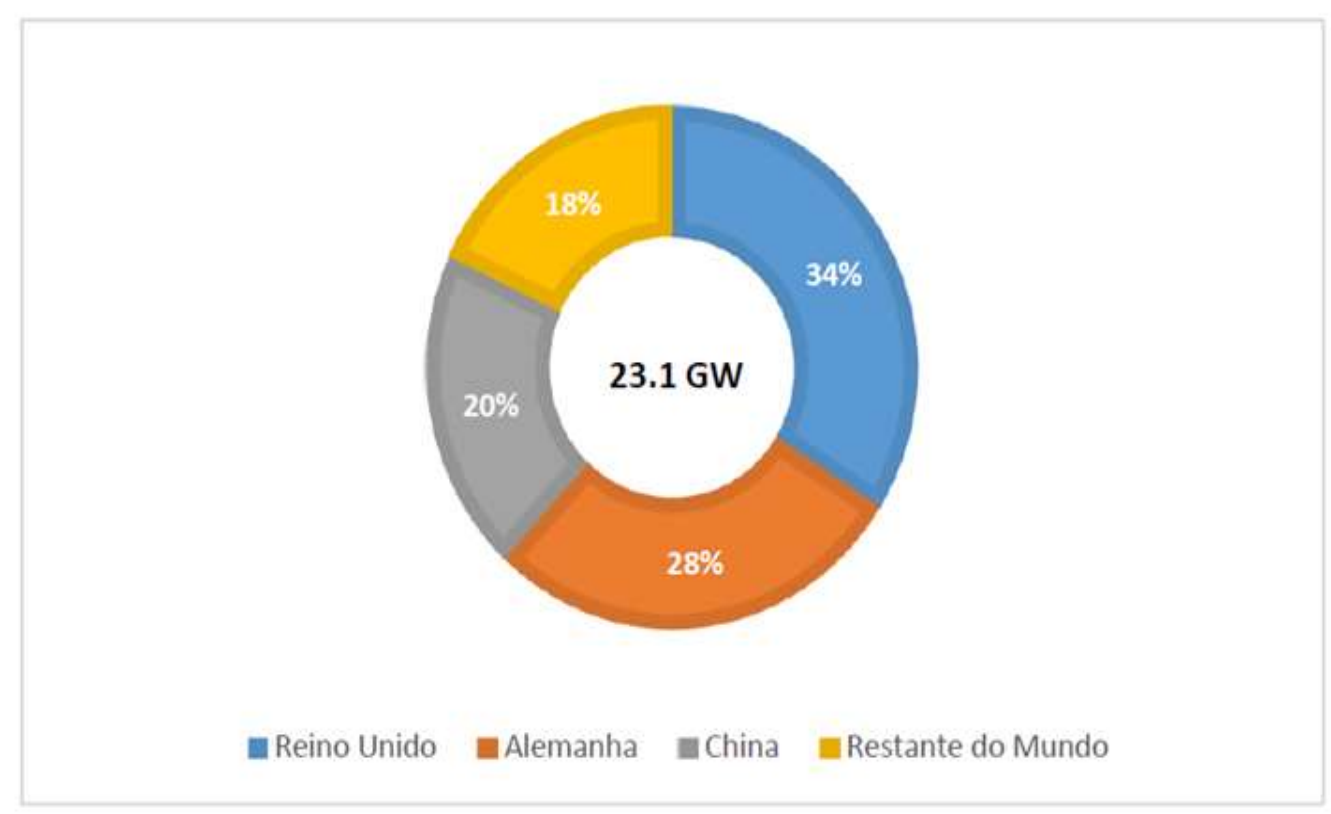

Fonte: ROADMAP Eólica offshore Brasil (2020)

O cenário nacional, por sua vez, se apresenta propicio para projetos de energia eólica dada as características peculiares do Brasil. No entanto, apesar de possuir um vasto território com grande potencial para geração de eletricidade a partir do vento, o país ainda apresenta produção retraída através dessa fonte (comparando com outras), mesmo sendo considerável o crescimento, nos últimos anos, da exploração dessa fonte renovável de energia.

Existiam cerca de 680 parques eólicos, até o ano de 2020, totalizando aproximadamente 7.900 turbinas eólicas no Brasil. A geração de energia eólica no País cresceu $15,5 \%$ no primeiro semestre de 2019 , em relação ao mesmo período em 2018, segundo a Câmara de Comercialização de Energia Elétrica (CCEE). Um fato positivo é que esses números crescem a cada ano, e, de acordo com Silva (2021) a energia eólica gerada, atualmente em todo o país, é utilizada por 90,5 milhões de pessoas. Além disso, pode abastecer cerca de 30,2 milhões de residências. Deste total, mais de 80\% dos parques eólicos 
já estavam instalados no Nordeste desde 2014, dada a intensidade dos ventos da região. (CCEE, 2014).

Atualmente, o Brasil tinha uma capacidade instalada de geração de $58 \mathrm{TWh}$ (em 2020), o que corresponde a cerca de 9,5\% da matriz elétrica nacional.

Afim de melhor ilustrar a capacidade de energia no país, a Figura 6 mostra como se apresenta distribuída a matriz energética brasileira, segundo a participação de cada fonte, conforme dados de IRENA(2021).

Figura 5 - Matriz Energética Nacional

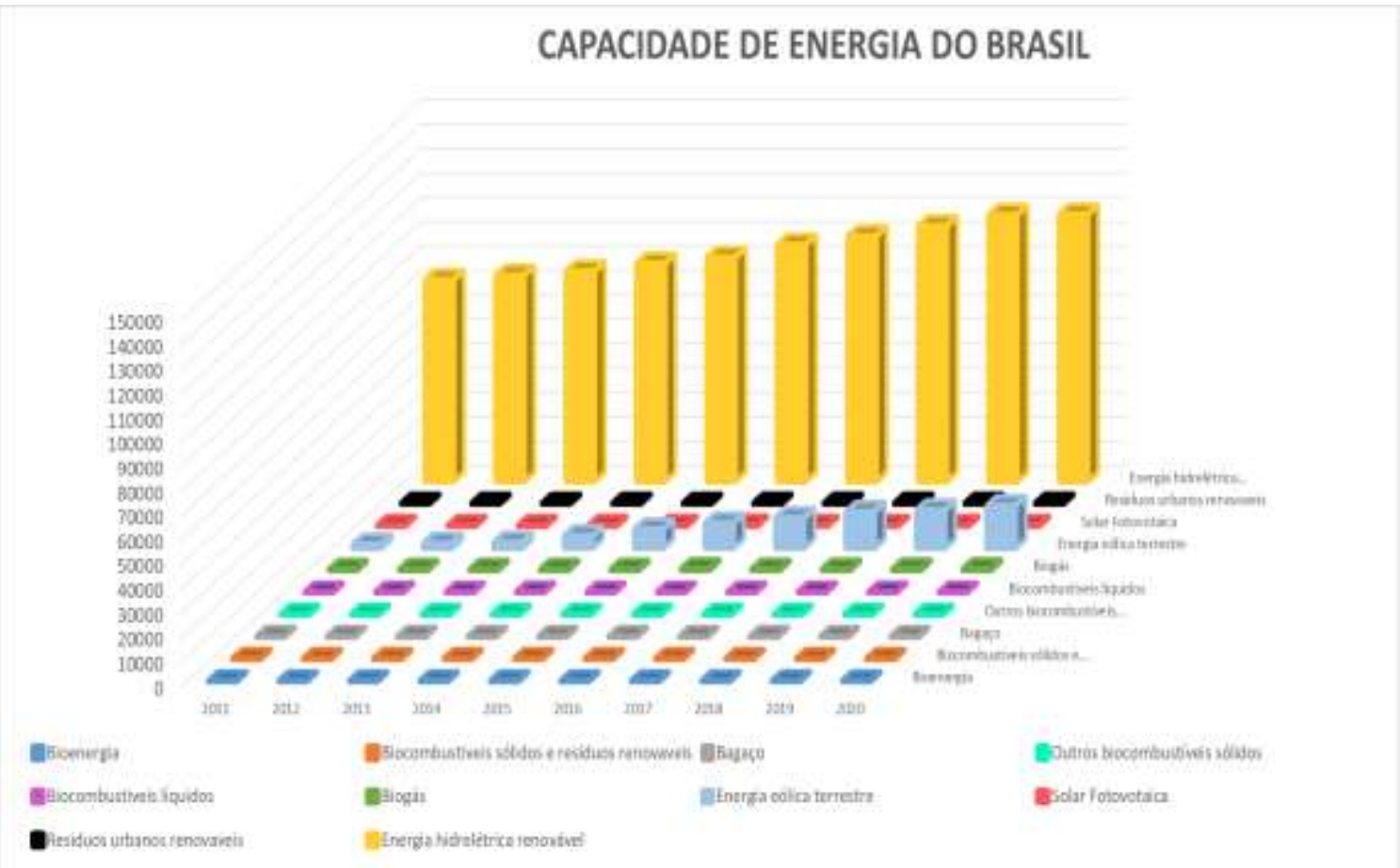

Fonte: IRENA, 2021.

Diante desse cenário e considerando um aumento na implantação de parques eólicos, este trabalho objetiva realizar uma análise comparativa entre parâmetros de investimentos eólico, hidrelétricos e termelétrico, durante o período de 2006 a 2016, realizando especificamente uma revisão bibliográfica sobre o tema, sintetizar aspectos relevantes relacionados aos critérios econômicos e ambientais de usinas eólicas e comparar com os de usinas hidroelétrica e termelétricas e propor alternativas de melhoria.

O custo de produção de energia pode ser mensurado de diversas maneiras, cada uma com sua peculiaridade, sendo voltadas para diferentes aplicações. Os custos podem ser extremamente detalhados, entretanto, está sendo feita uma análise genérica devido ao fato de obter resultados mais abrangente, e desconsiderar variabilidades de região para região. 
A análise econômica de uma turbina eólica é um aspecto estratégico das empresas e por isso os custos de produção não são compartilhados. Assim como as empresas não pagam com energia elétrica $(\mathrm{R} \$ \mathrm{KW}$ ) para construir um parque eólico no Brasil. (CPFL \& GESEL, 2015) (MANWELL, MCGOWAN, \& ROGERS, 2009).

O custo do investimento, o qual inclui aerogerador, fundação, instalação e a ligação à rede, apresentam variação em função do diâmetro do rotor, velocidade dos ventos e outros. Os custos de transporte de equipamentos para a construção de estações de trem, bem como a criação de estradas adequadas para facilitar o transporte representam os $19 \%$ do custo descrito na Figura 9. Outro componente de custos é o Custo de Operação e Manutenção (O\&M). Uma análise da Danish Wind Industry Association (2006), com base em dados compilados de 5.000 máquinas instaladas na Dinamarca, relatou que o custo de O\&M em 2006 foi em torno de $1,5-2,0 \%$ do custo de capital de uma empresa.

No Brasil, os serviços de O\&M são realizados pelos próprios fabricantes de aerogeradores em associação com empresas já estabelecidas no setor elétrico com experiência em outros tipos de usinas (como hidrelétricas e termelétricas). No entanto, o rápido crescimento da geração eólica nos últimos anos, tem causado dificuldades em relação aos serviços O\&M. A falta de mão de obra qualificada, conhecimentos específicos ainda pouco difundidos no setor e custos muitas vezes elevados são alguns dos desafios enfrentados pelos investidores para garantir essa função no prazo do projeto e de forma a evitar interrupções inesperadas (SIMOES, 2015).

Considerando o custo de O\&M igual a 2\% do custo de capital de um parque eólico no Brasil, o valor seria de aproximadamente R \$ 8 .ooo / MW a cada ano. Não foi encontrada informação sobre a variável custo de O\&M, portanto foi considerada igual a $R$ \$o / MWh.

Outro ponto de destaque, junto ao excelente potencial eólico do Brasil, os incentivos à implantação dessa fonte de geração e a crise internacional de 2oro, resultou em maior atratividade do mercado eólico e sua produção tem aumentado fortemente ano a ano. A Figura 6 mostra o desenvolvimento da geração eólica no Brasil e quanta eletricidade foi adicionada à matriz de 2006 a 2016. Dentre os principais estados brasileiros que já estão com energia eólica em operação estão: BA; RN; CE; RS; PI; MA; PE e PB.

O aumento da produção de parques eólicos e turbinas tem levado a uma redução dos custos de investimento, que também se reflete nos preços da energia negociados em 
leilões. O Programa de Incentivo às Fontes Alternativas de Energia Elétrica (PROINFA), definiu o preço médio de venda da energia em $\mathrm{R} \$ 366 / \mathrm{MWh}$. No primeiro leilão, em 2009, o preço caiu para 195 reais / MWh. Outras quedas vieram subsequentemente. A alta competitividade dessa fonte no setor de energia, bem como a tendência de manutenção ou até mesmo de ampliação dessa posição tornam evidentes a queda dos custos, através da constatação de que o preço do leilão caiu drasticamente e permaneceu em uma faixa praticamente constante, uma vez que os preços de venda da energia são baseados no custo de geração e investimento, mais um valor que resulte num retorno econômico do empreendimento.

Em se tratando de uma análise comparativa com usinas de carvão e hidrelétricas, os custos apresentam valores muito variáveis. Os custos de capital, operacionais e de combustível, dependem: da tecnologia usada para instalação; dos custos operacionais; de flutuações da taxa de câmbio; tipo de armazenamento; mineração; transporte e qualidade. Para o combustível, regime operacional da instalação e restrições ambientais (que podem aumentar o valor do projeto em até 30\%), embora os valores de custo mínimo e máximo sejam amplamente separados, os valores médios são sempre usados.

Os parâmetros para análise econômica de aerogeradores termelétricos, hidrelétricos e eólicos foram descritos por Tomalsquin (2016), e estão apresentados na Tabela I, através da qual é possível serem realizadas comparações entre Usinas Hidrelétricas (UHE), Usinas Termelétricas (UTE), e Centrais Geradoras Eólicas (EOL).

Tabela I - Parâmetros para Análise Econômica

\begin{tabular}{|c|c|c|c|}
\hline Parâmetros & Valores (UHE) & Valores (UTE) & Valores(EOL) \\
\hline $\begin{array}{ll}\text { Custo } & \text { de } \\
\text { investimento } & \end{array}$ & $\begin{array}{l}7.238 .300 \\
(\mathrm{R} \$ / \mathrm{MW})\end{array}$ & $6.656 .000(\mathrm{R} \$ / \mathrm{MW})$ & $\begin{array}{l}4.200 .000 \\
(\mathrm{R} \$ / \mathrm{MW})\end{array}$ \\
\hline Custo de O\&M Fixo & $\begin{array}{l}\text { 4I.6oo } \\
(\mathrm{R} \$ / M W . a n o)\end{array}$ & - & $\begin{array}{l}84.000 \\
(\mathrm{R} \$ / M W . a n o)\end{array}$ \\
\hline $\begin{array}{ll}\text { Custo de } & \text { O\&M } \\
\text { Variável } & \end{array}$ & $5,76(\mathrm{R} \$ / \mathrm{MWh})$ & 3I $\left(\mathrm{R}_{\$} / \mathrm{MWh}\right)$ & - \\
\hline Custo de Combustível & - & $\mathrm{I} 28\left(\mathrm{R}_{\$} / \mathrm{MWh}\right)$ & - \\
\hline Fator de Capacidade & $55 \%$ & $66 \%$ & $43 \%$ \\
\hline Vida Útil & 50 (anos) & 40 (anos) & 20 (anos) \\
\hline Tempo de Construção & 8 (anos) & 4 (anos) & 2 (anos) \\
\hline Payback & I2 (anos) & 9 (anos) & 8 (anos) \\
\hline
\end{tabular}

Fonte:(TOMALSQUIN, 2016b) e (TOMALSQUIN, 2016a) 
Os custos de operação e manutenção apresentados na Tabela I, denotam diferenças para cada tipo de fonte energética. No caso específico de EOL, podem ser reduzidos através de desenvolvimento de novas tecnologias que possam eliminar a dependência da prestação de serviços de $\mathrm{O} \& \mathrm{M}$ de empresas multinacionais, bem como a fabricação local de todos os componentes necessários para EOL. Esta fonte de energia é formada apenas por custos fixos, independente da produção anual, por se tratar de uma tecnologia nova e com menor oferta de empregos. Além disso, verifica-se que o custo com combustível ocorre somente em termelétricas, o qual varia de acordo com a disponibilidade, transporte e, para o carvão importado, o custo também muda com a variação da taxa de câmbio.

Considerando o tempo de construção, um grande parque eólico leva muito menos tempo para ser construído, o que gera receita mais rapidamente. No entanto, termelétricas e hidrelétricas do mesmo porte têm cerca de dez vezes maior capacidade de geração. Dividindo o tempo de construção pela capacidade da usina, uma forma ilustrativa de contabilizar a quantidade de tempo gasto por MW é obtida. Este cálculo fornece como resultado que o parque eólico leva mais tempo de construção para cada $\mathrm{MW}$ esperado. $\mathrm{O}$ Fator de Capacidade dos parques eólicos é o menor de todos devido à característica do vento intermitente, o que significa que haverá picos e vales na geração eólica. $O$ fator de capacidade das hidrelétricas é diretamente proporcional à quantidade de chuvas anuais.

As plantas de estoque podem armazenar água por períodos de seca, no entanto, eles não são suficientes se a seca for muito longa. As termelétricas têm um fator de capacidade próximo ao máximo, mas são acionadas apenas quando as hidrelétricas e outras fontes renováveis não conseguem atender à demanda, isto porque o custo operacional das fontes renováveis é muito menor. O payback destes investimentos atribuiu, segundo Tabela I, o melhor resultado para EOL, e isto se deve a redução do teto de financiamento por parte do BNDES (2016) .

\section{I -Análise Ambiental}

O uso da energia eólica traz benefícios importantes para o meio ambiente. Isso porque esse tipo de geração não emite quantidades significativas de gases poluentes, tanto na sua fabricação quanto na sua operação. A redução das emissões de gases significa uma melhor qualidade de vida e valoriza a conservação do meio ambiente (MANWELL, MCGOWAN, \& ROGERS, 2009). No entanto, as fontes renováveis também apresentam 
aspectos ambientais negativos. Iniciando por identificar os aspectos positivos e negativos potenciais associados à instalação de um parque eólico, serão comparados com as usinas hidrelétricas e termelétricas a carvão.

Além dos benefícios ambientais, os desenvolvimentos sociais gerados por essas empresas são considerados importantes dado a atração de investimentos em áreas desfavorecidas, a criação de novos empregos e a possibilidade de aproveitamento do terreno com parques eólicos. Vale citar, por exemplo, a concentração de aerogeradores na região Nordeste, que é uma das áreas menos desenvolvidos do país. Assim, abrem-se novas fontes de renda para a sociedade local e atrai turistas para regiões remotas e carentes, aumentando vendas e desenvolvimento da região. A variabilidade da matriz energética, que reduz o risco de novas faltas de energia e do uso de termelétricas, também é avaliada como um efeito positivo. Os possíveis efeitos negativos de um parque eólico estão apresentados a seguir.

No que se refere ao impacto sob a fauna, existem espécies de pássaros que são muito sensíveis às mudanças em seu habitat e neste caso, o investimento requer critérios muito amplos na escolha de um local para parques eólicos, bem como monitoramento contínuo visto que as turbinas eólicas têm alguns efeitos na vida das aves como mortalidade por colisão, mudanças nos hábitos migratórios, alimentares e reprodutivos e redução do habitat.

Além da escolha do local correto, diversas medidas podem ser tomadas para mitigar os efeitos. A instalação de dispositivos de radar para detectar bandos de pássaros que se aproximam, o que requer a parada das turbinas é uma alternativa citada por (DERMOTT, 2009). Construção de menos turbinas em dimensões maiores, que reduz a velocidade e o número de estruturas. Construção de linhas de transmissão subterrâneas para evitar que aves sejam eletrocutadas. Mudança no desenho de torres e treliças está ligada à maioria dos óbitos.

Infelizmente, muitos dos locais com grande potencial eólico também são atraentes para os pássaros. No caso do Brasil, as regiões Nordeste e Sul possuem rotas aéreas importantes para aves migratórias de longa distância, incluindo algumas protegidas internacionalmente. Assim, dependendo da localização, além das medidas de mitigação recomendadas, novos estudos sobre licenças ambientais devem ser realizados. 
Outro fator considerado como importante, o impacto visual. Este é um critério difícil de quantificar, pois depende do ponto de vista, da localização do parque e de outros fatores. Apesar da natureza subjetiva, os profissionais realizam esta análise com base em conhecimento da composição visual do meio e na identificação de elementos como clareza visual, harmonia, equilíbrio, ordem e hierarquia. Por isso se torna mais apropriado quando não há grandes mudanças no ambiente original. Porém, a melhor forma de reduzir essa perturbação é escolher locais que já sejam antropogênicos ou áreas de pouco interesse turístico. Outra forma de mitigar esse problema seria usar projetos arquitetônicos como um plano B, alterar a geometria do layout da turbina, pintar as lâminas, a escolha estética das estruturas, etc. (STANTON, 2006).

A poluição sonora também é um fator considerado porque o problema associado ao ruído das turbinas eólicas é um dos impactos ambientais estudados no setor de geração de energia eólica. Este ruído depende de fatores como: nível de intensidade, frequência, distribuição de frequência, distância entre transmissor e receptor e tipo de receptor. $E$ as consequências podem ser de irritabilidade, desconforto, comprometimento do sono ou de estudo e efeitos psicológicos (ansiedade, zumbido nos ouvidos ou perda auditiva).

Já o uso do solo é muito maior que nas demais tecnologias visto a necessidade de uma distância mínima entre as turbinas para que a interferência de vento seja reduzida e a geração de energia, consequentemente maximizada. (MANWELL; MCGOWAN; ROGERS, 2009). Há duas opções quando se trata de terrenos: comprar ou alugar. Comprar tem um custo mais alto e desperdiça terreno, pois os incorporadores não usariam o terreno restante para terceiros. Por outro lado, o arrendamento é economicamente mais rentável, pois os pagamentos são distribuídos ao longo da vida do empreendimento e os proprietários, além de possuírem uma fonte diversificada de renda, também podem utilizar os terrenos baldios para a agricultura (NETO \& VIEIRA, 2009)

$\mathrm{O}$ arrendamento do terreno deve incluir cláusulas que mantenham a integridade do parque eólico e aerogeradores para os promotores, como evitar o plantio de árvores, ou edifícios muito altos a uma distância mínima, bem como proibição de caça de animais e queima de cana do açúcar, pois podem danificar as turbinas. Também devem ser criadas condições para a conservação do território, como a previsão de possíveis danos e o posterior pagamento de indenizações. O NWCC (20II) propõe algumas medidas para amenizar a natureza industrial do projeto e manter a integridade do terreno: escolha de 
equipamentos com suporte estrutural mínimo; uso de linhas de energia subterrâneas; construção de turbinas maiores e mais eficientes em menor quantidade, de modo a evitar a construção de estradas para reduzir perda de terreno, que limita uso de vias de acesso a veículos.

\subsection{Análise Comparativa}

Considerando que cada tipo de planta causa impactos específicos e, em geral, diferentes, os critérios mais abrangentes foram escolhidos para a análise, a saber:

\section{Emissões de gases nocivos ao meio ambiente}

De acordo com o IPCC (2012), os gases liberados pelas hidrelétricas são os menos nocivos ao meio ambiente entre as formas de geração que contribuem para o efeito estufa (GEE). As termelétricas a carvão têm a maior taxa média de $\mathrm{CO}^{2}$ (cerca de 250 vezes mais do que a energia hidrelétrica). A Tabela 2 mostra os valores máximos, mínimos e médios de emissão de $\mathrm{CO}^{2}$ dos três tipos de usinas comparados.

Tabela 2 - Emissões de $\left(\mathrm{kg} \cdot \mathrm{CO}^{2}\right) / \mathrm{MWh}$ por fonte de geração.

\begin{tabular}{llll} 
Valores & Hidrelétricas & $\begin{array}{l}\text { Energia } \\
\text { Eólica }\end{array}$ & Carvão \\
\hline Mínimo & 0 & 2 & 675 \\
$50 \%$ & 4 & I2 & 1001 \\
Máximo & 43 & $8 \mathrm{I}$ & 1689 \\
\hline
\end{tabular}

Fonte: IPCC (2012)

Estima-se que o carvão seja responsável por 30,5\% das emissões totais de $\mathrm{CO}_{2}$ do mundo. Além do dióxido de carbono, as termelétricas emitem grandes quantidades de nitrogênio, enxofre, hidrocarbonetos, monóxido de carbono ( $\mathrm{NOx}, \mathrm{SO}_{2}, \mathrm{HC}$ e $\mathrm{CO}$ ) e material particulado, que afetam tanto o aquecimento global quanto a ocorrência de chuva ácida A Tabela 3 mostra as taxas de emissão dos componentes nomeados da combustão de carvão duro por usinas de geração de energia.

Tabela 3 - Emissão de gases e material particulado na combustão do carvão mineral

\begin{tabular}{lllll}
\hline Material & $\mathrm{SO}_{2}$ & $\mathrm{NO}_{X}$ & $\mathrm{HC}$ & $\mathrm{CO}$ \\
particulado & $(\mathrm{kg} / \mathrm{t})$ & $(\mathrm{kg} / \mathrm{t})$ & $(\mathrm{kg} / \mathrm{t})$ & $(\mathrm{kg} / \mathrm{t})$ \\
\hline
\end{tabular}




\begin{tabular}{lllll}
\hline$(\mathrm{kg} / \mathrm{t})$ & & & & \\
\hline 20,00 & 3,8 & 9,0 & 0,15 & 0,5 \\
\hline
\end{tabular}

Fonte: (PNE 2030, 2007)

As taxas de emissão de GEE das usinas termelétricas poderiam ser drasticamente reduzidas com o uso de novas tecnologias para sua produção e o uso de carvão de alta qualidade. Porém, provenientes da década de 1970, termelétricas a carvão no Brasil são muito antigas, não possuem tecnologias atuais, e o carvão disponível é considerado de baixa qualidade.

Apesar do baixo índice de emissão das barragens, sua construção em áreas tropicais pode causar a emissão de gás metano $\mathrm{CO}_{2}$ e $\mathrm{CH}$ devido à decomposição da matéria orgânica inundada. Esses dois gases são os principais contribuintes para o efeito estufa, sendo o metano 32 vezes mais poluente que o dióxido de carbono (FARIA, 2015). Se as hidrelétricas são construídas em locais com muita matéria orgânica, embora não sejam queimadas para gerá-la, elas têm um alto índice de emissões de $\mathrm{CO}_{2}$ nos primeiros 20 anos. Os próximos 30 anos de vida útil que essas instalações geralmente possuem seriam basicamente para pagar pela quantidade de gases emitidos nos primeiros 20 anos.

\subsection{Impacto na flora e fauna}

O Brasil possui um grande potencial hidrelétrico da ordem de $173 \mathrm{GW}$, dos quais 68 GW ainda não utilizados. As bacias hidrográficas do Amazonas e Tocantins do Araguaia representam 66 do potencial inexplorado do país. Ambas estão localizadas na região Norte, que tem a Mata Atlântica como bioma e a planície como relevo, o que significa que são áreas protegidas com grande variedade de fauna e época e que precisam de barragens maiores para formar um gerador de energia de cascata elétrica.

A construção de barragens é o fator mais relevante no impacto ambiental das usinas hidrelétricas. Quanto maior a barragem, maior a planície de inundação, e assim, há perda de animais terrestres, que em muitos casos não têm agilidade para escapar de enchentes e, em outros, não conseguem adaptação ao novo habitat; além da perda da vegetação local. (MENDES, 2005) 
A hidrelétrica também influencia a vida aquática do rio inserido neste contexto, pois a construção das barragens, muda o balanço hídrico, que não tem mais movimento ou corrente para comportar-se naturalmente como antes. Essa mudança altera a vida de peixes, que usam a locomoção das águas para reprodução (JONG, KIPERSTOK, \& TORRES, 2015)

Já o combustível queimado em uma termelétrica, tem seu calor convertido em água e se transforma em vapor, que alimenta a turbina. Para que esse processo ocorra, os sistemas termelétricos devem ser instalados próximos ao leito dos rios ou ao mar. Isso leva a um aumento da temperatura da água local à medida que se torna mais quente, o que pode afetar a fauna e a flora da região e aumentar a temperatura média local. Esses são apenas os efeitos diretos na fauna. $\mathrm{Na}$ queima do combustível, muitos gases são liberados elevam o clima global e acidificam as águas (INATOMI \& UDAETA, 2014)

Os efeitos cumulativos da chuva ácida afetam o meio ambiente (colheitas, materiais, água). Lagos ácidos lutam para manter capturas de peixes; o ácido pode retardar o crescimento das árvores e danificar o solo; reduzir campos rurais e danificar plantas. $\mathrm{O}$ aumento do clima global devido ao efeito estufa provocam degelo das calotas polares, secas severas e aumento de incêndios. Todos esses aspectos têm impacto direto na flora e na fauna.

Os animais da região ártica, por exemplo, estão perdendo cada vez mais espaço para sobreviver; secas severas causam escassez de água em certas regiões, afetando a vida de muitos animais; os incêndios matarão um grande número de outros animais, bem como a hora local; e a mudança dos níveis de água pode inundar regiões e causar destruição de corais e recifes, levando à extinção de várias espécies de peixes e plantas (MACMILLAN, 2016).

Em suma, a construção de uma usina hidrelétrica devasta toda a área da barragem e ainda eleva a taxa de mortalidade dos animais terrestres e aquáticos. Os sistemas termoelétricos não afetam apenas a vida aquática e terrestre em nível local, mas também todos os tipos de fauna e, às vezes, a poluição do ar global.

No caso dos parques eólicos, a devastação só ocorre nos locais onde as turbinas são utilizadas ( $5 \%$ da área causa de taxa de morte de pássaros de $0,4 \% / \mathrm{kWh}$ ). Porém, este número é desprezível em relação às termelétricas, que apresentam a maior parte dessas vidas salva. (SOVACOOL, 2009) 


\subsection{Problemas Ambientais na Sociedade}

As cheias das hidroelétricas provocam a expulsão da população local, desintegrando seus costumes e tradições, e a relação com o rio (tipo de agricultura desenvolvida, técnicas de rega, regime aluvial e relação sociocultural). É necessário realocar essa população, oferecendo uma realidade o mais próximo possível da anterior, o que raramente acontece. Além do deslocamento forçado, cuja compensação financeira permanece irrisória ou inexistente, tribos indígenas tem dificuldade de adaptação, por forte relação com essas terras.

As barragens também causam doenças endêmicas nas comunidades próximas às fábricas, incluindo doenças parasitárias como xistossomose e malária e, em menor proporção, febre amarela e dengue. Isso porque represas e sistemas de irrigação criam remansos e um ambiente propício ao surgimento e reprodução de insetos, caramujos e outros animais que servem como vetores para o desenvolvimento de parasitas (Coletiva, 2006)

Os poluentes emitidos pelas termelétricas são extremamente nocivos à saúde. A Organização Mundial da Saúde (OMS) anunciou em seu relatório que a população mundial de 80 anos está exposta a poluentes acima dos valores-limite recomendados. À medida que a qualidade do ar se deteriora, os riscos de acidentes vasculares cerebrais, doenças cardíacas, câncer de pulmão e doenças respiratórias crônicas e agudas aumentam, sendo os idosos, as crianças e os doentes crônicos as maiores vítimas. Estima-se que i2,6 milhões de mortes no mundo estão associadas à poluição e riscos ambientais (MATSUURA \& BAIMA, 20I6). O problema de saúde registrado em turbina eólica é o incômodo do ruído, que, dependendo da proximidade e da exposição, pode causar tonturas, dores de cabeça ou perda de audição. No entanto, essas experiências só podem ser vividas por trabalhadores de plantas industriais. E ainda podem ser evitados com os equipamentos de segurança adequados.

A construção de novas usinas, sejam hidrelétricas, eólicas ou termelétricas, tem o efeito de atrair trabalhadores e moradores para regiões menos povoadas e promover o desenvolvimento econômico dessas regiões menos desenvolvidas. No entanto, grandes usinas hidrelétricas e termelétricas têm pelo menos três vezes o tamanho de uma turbina eólica e, portanto, exigem um planejamento antecipado, pois podem gerar um rápido 
desenvolvimento para o qual a região e a população local podem não estar preparados, principalmente em infraestruturas como a falta de escolas, habitação, aterros, capacidade hospitalar, transporte, aumento da violência etc.

\section{CONCLUSÕES}

Com o surgimento da crise hídrica no Brasil, o que ocasionou o contínuo acionamento de termoelétricas, o aumento dos preços de venda de energia e o aumento das taxas de emissão de GEE, foi reconhecido na matriz energética pós-2003. A partir de 2003, foi descoberto o potencial eólico do país e elaboradas várias orientações para incentivar a construção de turbinas eólicas. Devido ao caráter emergencial da implantação de novas instalações, o Brasil não considerou necessário investir em pesquisa e estudo de tecnologia, uma vez que deu prioridade ao investimento externo direto de indústrias estrangeiras, sobretudo através de licenciamentos e consórcios de exploração.

No tocante as usinas hidrelétricas brasileiras, estas continuam sendo a fonte de geração mais lucrativa, uma vez que seus custos operacionais são significativamente menores, apesar dos maiores custos de investimento, e seu prazo de retorno ser próximo ao das termoelétricas. Além do alto custo de investimento unitário, a construção da UHE (Usina de energia eólica) requer grande capacidade e uma grande quantidade de capital total e tempo para operar. Portanto, podem surgir dificuldades na rentabilidade desses projetos devido à difícil disponibilidade de recursos financeiros e às condições de financiamento. $\mathrm{O}$ diferencial brasileiro é que, uma das principais vantagens comparativas em relação à grande maioria dos países, se trata de um país com potencial energético e com grande diversidade de energias limpas. No caso de eólicas, é fato que o país possui um dos melhores ventos do mundo, o que significa energia muito competitiva. Um critério tão importante quanto a eficiência econômica é o impacto ambiental associado a esta fonte. A geração eólica tem maior vantagem sobre este critério, pela baixa emissão de gases que contribuem para o efeito estufa, o uso de fonte renovável, o fato de não exigir incineração para gerá-la e a pouca interferência na fauna local.

Se faz necessário, ainda, por conta da extensa área costeira do pais, um plano holístico de gestão costeira, composto por: uma divisão em zonas marítimas de modo a manter o equilíbrio no que se refere a implantação das atividades de energia eólica offshore e demais atividades existentes neste ambiente, em termos econômicos, ambientais, sociais 


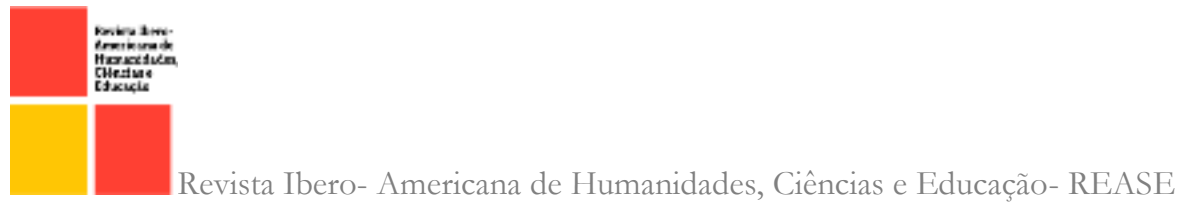

e de segurança; levantando considerações como delimitação de profundidade, rotas de navegação, impactos ambientais com a compensação dos danos ecológicos do ecossistema marinho (os quais permitem a internalização das externalidades das ações antrópicas de forma eficiente). Além de um melhoramento do sistema legislativo e maior capacidade de gestão baseada no levantamento do estado atual da área costeira do pais de modo que os projetos de desenvolvimento e conservação costeiros sejam baseados em informações fidedignas e seja mantida a qualidade ambiental das aguas.

Algumas sugestões para um uso otimizado da energia eólica no Brasil seriam a interligação do sistema elétrico brasileiro com o de outros países. Essa energia poderia ser vendida para outros países em épocas de superávit e comprada em épocas de déficit, priorizando energia de fontes renováveis. Além disso, mais pesquisas sobre os ventos brasileiros devem acontecer para melhorar a tecnologia de previsão e aprimorar mais conhecimento sobre o comportamento do vento, visto que dependendo do resultado da intensidade do vento em cada região, os sistemas podem ser implantados em locais estratégicos com complementaridade das velocidades verificadas. Restrições ambientais mais rígidas sobre o uso dos equipamentos também são necessárias para priorizar o uso de equipamentos menos poluentes.

\section{REFERENCIAS BIBLIOGRAFICAS}

AIE (2021). Renewable Energy Market Update. 2021, IEA, Paris. Agência Internacional de Energia. Disponível: https://www.iea.org/reports/renewable-energy-market-update202I.

EPE - Empresa de Pesquisa Energética (Brasil). Balanço Energético Nacional 2020: Ano base 2019 / Empresa de Pesquisa Energética. - Rio de Janeiro: EPE, 2020.

ARAÚJO, M. Estudo comparativo de sistemas eólicos utilizando modelos probabilísticos de velocidade do vento. COPPE/UFRJ, 1989.

BNDES. BNDES divulga novas condições de Financiamento a energia elétrica. 2016. Acessado: I9-II-202I. Disponível em: 〈http://www.bndes.gov.br >.

CADERNO SAÚDE COLETIVA. UFRJ, 2006. Disponível: $<$ http://www.cadernos.iesc.ufrj.br/ cadernos/images/csc/2006_4/artigos/CSC_NESC_ 2006-Fabiola.pdf $>$.

CAMPOS, F. G. R. Geração de Energia Eólica a Partir de Fonte Eólica com Gerador Assíncrono Conectado a um Conversor Estático Duplo. 2004. Dissertação (Mestrado em Sistemas de Potência) - Escola Politécnica, Universidade de São Paulo, São Paulo, 2004. doi:10.11606/D.3.2004.tde-25062004-130205. 
CPFL; GESEL. Panorama e Análise Comparativa da Tarifa de Energia Elétrica do Brasil com Tarifas Praticadas em Países Selecionados, Considerando a Infuência do Modelo Institucional Vigente. p. 397, 2015.

CRESESB. Mecanismo de Geração dos Ventos. 2014. acessado: 28-or-2016. Disponível em: $\langle$ http://www.cresesb.cepel.br/index.php?section=com_content\&lang=pt\&cid=2II .

DANISH WIND INDUSTRY ASSOCIATION. Guided Tour on Wind Energy. 2006. Acessado: 25-II-202I. Disponível em: 〈http://www.windpower.org/en/tour.htm〉.

DERMOTT, M. M. Texas wind farm uses nasa radar to prevent bird de- aths. 2009. Disponível:<http://www.treehugger.com/ les/2009/5/texas-wind-farm-uses-nasa-radarprevent-bird-eaths.php;>.

EPE. Plano Decenal de expansão de Energia 2024. [S.1.], 2015. 467 p. Disponível em:

〈http://www.epe.gov.br/PDEE/Relat\%C3\%B3rio\%2oFinal\%2odo\%2oPDE\%202024〉.

FARIA, F. A. M. de et al. Estimating greenhouse gas emissions from future amazonian hydroelectric reservoir. IOP Science, Environmental Research Letters, 2015. Disponível em: 〈http://iopscience.iop.org/article/ro.1088/1748-9326/10/12/124019/pdf〉.

INATOMI, T. A. H.; UDAETA, M. E. M. Análise dos impactos ambientais na produção de energia dentro do planejamento integrado de recursos. USP, 2014.

IPCC. Special report on renewable energy sources and climate change mitigation (srren). Cambridge University Press, 2012.

IRENA (202I), Estatísticas de capacidade renovável 202I Agência Internacional de Energia Renovável (IRENA), Abu Dhabi.

JONG, P. de; KIPERSTOK, A.; TORRES, E. A. Economic and environmental analysis of electricity generation technologies in brazil. Renewable and Sustainable Energy. Reviews, Elsevier Ltd, p. 726 735, 2015. Disponível em: 〈http://linkinghub.elsevier.

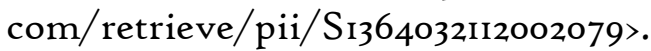

LAGE, Elisa Salomão; PROCESSI, Lucas Duarte. Panorama do setor de energia eólica. Revista do BNDES, Rio de Janeiro, n. 39, p. 183-205, jun. 2013.

MACMILLAN, A. Global Warming. 2016. Disponível em: 〈https://www.nrdc.org/stories/global-warming-ıoı.

MANWELL, J.; MCGOWAN, J.; ROGERS, A. Wind energy explained: theory, design and application. [S.1.]: Wiley, 2009. 577 p.

MATSUURA, S.; BAIMA, C. OMS: $80 \%$ da população urbana mun- dial vive sob níveis nocivos de poluição. Disponível em: <http://oglobo.globo.com/sociedade/sustentabilidade/oms-8o-Da-populacao-urbanamundial-vive-sob-niveis-nocivos-de-poluicao-I9296625>. 
MAUAD, F. F., FERREIRA, L. d., \& TRINDADE, T. C.. Energia renovável no Brasil: Análise das principais fontes energéticas renováveis brasileiras. São Carlos: EESC/USP. 2017.

MENDES, N. A. S. As usinas hidrelétricas e seus impactos: os aspectos socioambientais e econômicos do reassentamento rural de Rosana- Euclides da cunha paulista. Unicamp, 2005 .

NETO, J. A. R. G. aes; VIEIRA, R. Energia eólica - atração de investimentos no estado do Ceará. 2009. Disponível em: <http://investimentos.mdic.gov. $\mathrm{br} /$ public/arquivo/arq1321639117.pdf>.

NWCC. Permitting of wind energy facilities: A handbook. RESOLVE, National Wind Coordinating Committe, 201r. Disponível em: http://www.nationalwind.org/publications/siting/nwcchr.pdf>.

PINTO, R.J.; SANTOS, V.M.L. Energia Eólica no Brasil: evolução, desafios e perspectivas. Journal on Innovation and Sustainability - RISUS, vol. Io, no $1-$ 2019. ISSN: $2179-3565$.

PNE 2030. Geração Termelétrica - Carvão Mineral. 2007. Disponível em: 〈http://www.epe.gov.br/pne/forms/empreendimento.aspx $>$.

PROINFA - ELETROBRAS. 2010. Acessado: 30-II-202I. Disponível em: hhttp: //www.eletrobras.com/elb/ProinfA/data/Pages/LUMISABB6ID26PTBRIE.htm>.

REIS, L. B. dos. Geração de Energia Elétrica. [S.1.]: Manole Ltda, 2oIr.

ROADMAP Eólica offshore Brasil. 2020.

SANSIGOLO, C. A. Distribuição de probabilidade de velocidade de potência do vento. Revista Brasileira de Meteorologia, p. 207 214, 2005.

SCR. Evolução da Energia Eólica no Brasil. 2016. Disponível em: <http://www.aneel.gov.br/aneel-essencial/-/asset_publisher/c4M6OIoMkLad/content/ evolucao-da-energia-eolica-no-brasil?inheritRedirect $=$ false $>$.

SHI, W. et al. Feasibility study of offshore wind turbine substructures for southwest offshore wind farm project in Korea. Renewable Energy, v. 74, p. 406-413, 2014.

SIGD. Sistema de Informação para Geração Distribuída de Energia. mapa de vento desenvolvido a partir do Atlas Eólico Brasileiro. Acessado: 17/10/2021. Disponível em https://www.ufrgs.br/sieolica/mapaeolicora.html.

SIMIS, A. Análise de viabilidade econômica de projetos de geração eólica no brasil. 2010.

SIMOES, V. O\&M para usinas eólicas em operação torna-se um dos maiores desafios para o setor em crescimento no país. 2015. Disponível em: 〈http://blogenergia.cfa.com.br $>$. 
SOVACOOL, B. Contextualizing avian mortality: a preliminary appraisal of bird and bat fatalities drom wind fossil-fuel and nuclear electricity. Energy Policy, p. 224I 2248, 2009.

STANTON, C. The landscape impact and visual design of windfarms. School of Landscape Architeture, p. Landscape Publicashion No. LP/9603, 1996.

TOMALSQUIN, M. T et. Al. Matriz energética brasileira. Revista Novos Estudos, novembro, 2007.

TOMALSQUIN, M. T. Energia renovável: Hidráulica, biomassa, eólica, solar e oceânica. EPE, p. 452, 2016b. Disponível em: ttp://www.epe.gov.br/Documents/Energia\% 2oRenov\%C3\%Arvel\%20-\%20Online\%2016maiozor6.pdf $>$.

TOMALSQUIN, M. T. Energia termelétrica: Gás natural, biomassa, carvão, nuclear. EPE, p. 417, 2016. Disponível em: <http://www.epe.gov.br/Documents/Energia\% 2oTermel\%C3\%Agtrica\%20-\%20Online\%2013maiozor6a.pdf>.

TEMPORINI, E. R. \& PIOVESAN, A.(1995). Pesquisa exploratória: procedimento metodológico para estudo de fatores humanos no campo da saúde pública. Revista Saúde Pública, 29(4), 318-325.

TROEN, I.; PETERSEN, E. L. European wind atlas. Riso National Laboratory, 1989.

TUCHTENHAGEN, P.; BASSO, J.; YAMASAKI, Y. Avaliação do potêncial eólico brasileiro em 201r. Ciencia e Natura, p. 390 40I, 2014. Disponível em: $\langle$ http://cascavel.ufsm.br/revistas/ojs-2.2.2/index.php/cienciaenatura/article/view/13148〉. 